\title{
Speed models for motorcycle riders for two-lane rural roads
}

\author{
PANAGIOTIS LEMONAKIS ${ }^{1}$, GEORGE BOTZORIS ${ }^{2}$, \\ ATHANASIOS GALANIS ${ }^{3}$, NIKOLAOS ELIOU ${ }^{1}$ \\ ${ }^{1}$ Department of Civil Engineering, Section of Transportation, University of Thessaly, \\ Pedion Areos, 38334 Volos, GREECE \\ ${ }^{2}$ Department of Civil Engineering, Section of Transportation, Democritus Thrace University, \\ Kimmeria Campus, 67100 Xanthi, GREECE \\ ${ }^{3}$ Department of Civil Engineering, International Hellenic University, \\ Terma Magnesias, 62124 Serres, GREECE
}

\begin{abstract}
The development of operating speed models has been the subject of numerous research studies in the past. Most of them present models that aim to predict free-flow speed in conjunction with the road geometry at the curved road sections considering various geometric parameters e.g., radius, length, preceding tangent, deflection angle. The developed models seldomly take into account the operating speed profiles of motorcycle riders and hence no significant efforts have been put so far to associate the geometric characteristics of a road segment with the speed behavior of motorcycle riders. The dominance of 4-wheel vehicles on the road network led the researchers to focus explicitly on the development of speed prediction models for passenger cars, vans, pickups, and trucks. However, although the motorcycle fleet represents only a small proportion of the total traffic volume motorcycle riders are over-represented in traffic accidents especially those that occur on horizontal curves. Since operating speed has been thoroughly documented as the most significant precipitating factor of vehicular accidents, the study of motorcycle rider's speed behavior approaching horizontal curves is of paramount importance. The subject of the present paper is the development of speed prediction models for motorcycle riders traveling on two-lane rural roads. The model was the result of the execution of field measurements under naturalistic conditions with the use of an instrumented motorcycle conducted by experienced motorcycle riders under different lighting conditions. The implemented methodology to determine the most efficient model evaluates a series of road geometry parameters through a comprehensive literature review excluding those with an insignificant impact to the magnitude of the operating speeds in order to establish simple and handy models.
\end{abstract}

Key-Words: -Motorcyclists' behavior, Horizontal curves, Curvature, Speed model, Field measurements, Naturalistic riding study

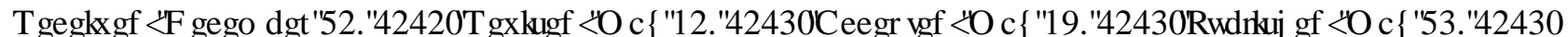

\section{Introduction}

The correlation between road geometry and driving behavior has been extensively studied in the past. Most of the researchers and organizations inferred that speeding is the most significant contributory factor to road traffic accidents both in terms of accident severity and frequency of occurrence $[1,2$, $3]$. Hence the investigation of the factors that affect driver's speed choice is of paramount importance to the road user's safety. Such factors include, among others, a series of geometric features for instance the degree of curvature and the radius of the horizontal curves as discussed in a report, published by the Federal Highway Administration in the United
States [4]. The developed models that incorporate the operating speeds of the vehicles with the various parameters of the road geometry were then evaluated depending on the value of the coefficient of determination. However, none of these models consider the travel speed of motorcycle riders and therefore the correlation between rider's speed choice with the road geometry is still vague [5].

The only attempt to model the operating speed of power two-wheelers and passenger cars' drivers performed by Perco [6]. His model is however limited to urban areas and additionally, it merely indicates the ratio of the operating speeds between these two vehicles without considering any elements 
of the road geometry. Conversely, Faezi et al. developed a model that predicts motorcycle speed in conjunction with the lane width, deflection angle, and the length of the tangent but their model is only applicable to exclusive motorcycle lanes [7].

The knowledge of the operating speed, i.e., the speed which most of the drivers (85\%) do not exceed in a road segment or an individual element of the road, e.g., horizontal curve or tangent, is crucial for the safety and consistency of a highway design. That will allow evaluating a road section in safety terms based on the difference between the values of the operating speed and the design speed. When this difference is above a threshold, e.g., 20 $\mathrm{km} / \mathrm{h}$, then the highway design is considered poor and re-design is required aiming at reducing this difference to an acceptable value [8].

As a consequence, the development of regression models based on the observations of the travel speeds of the vehicles is the first step to evaluate the design consistency of a road. Moreover, the importance of the geometric design on traffic safety has been thoroughly investigated by numerous researchers $[9,10,11]$ and hence, most of the developed speed prediction models so far take into account the contribution of the road segment's attributes to the estimated speed.

Against this background, the literature review regarding the development of operating speed models oriented to motorcycle riders is very limited, particularly for rural 2-lane roads. The present paper aims to bridge this gap by investigating motorcyclists' speed behavior in a two-lane rural road and propose a model that predicts the operating speed of motorcycle riders. The methodology adopted, involved the execution of field measurements under naturalistic conditions with the use of an instrumented motorcycle. Subjects of the measurements were male experienced riders, all members of a motorcycle club.

\section{Field Measurements}

The design of the field measurements was based on the selection of three fundamental elements: the participants, the vehicle, and the road environment. The first element was fulfilled with the implementation of a questionnaire-based survey. The survey concluded with the selection of 18 male riders who rode an instrumented motorcycle along both directions of a 2-lane rural road segment. The experimental road environment (from $39^{\circ} 18^{\prime} 08.2^{\prime \prime} \mathrm{N}$ $22^{\circ} 54^{\prime} 47.6^{\prime \prime} \mathrm{E}$ to $\left.39^{\circ} 17^{\prime} 01.8^{\prime \prime} \mathrm{N} 22^{\circ} 50^{\prime} 15.9^{\prime \prime} \mathrm{E}\right)$ constituted of 21 horizontal curves covering 5,100 $\mathrm{m}$ and tangents of 2,538 m length (Fig. 1) and it is part of the Volos - Karditsa highway located in central Greece. Therefore, the total length of the road where the field measurement took place was approximately $7,638 \mathrm{~m}$.

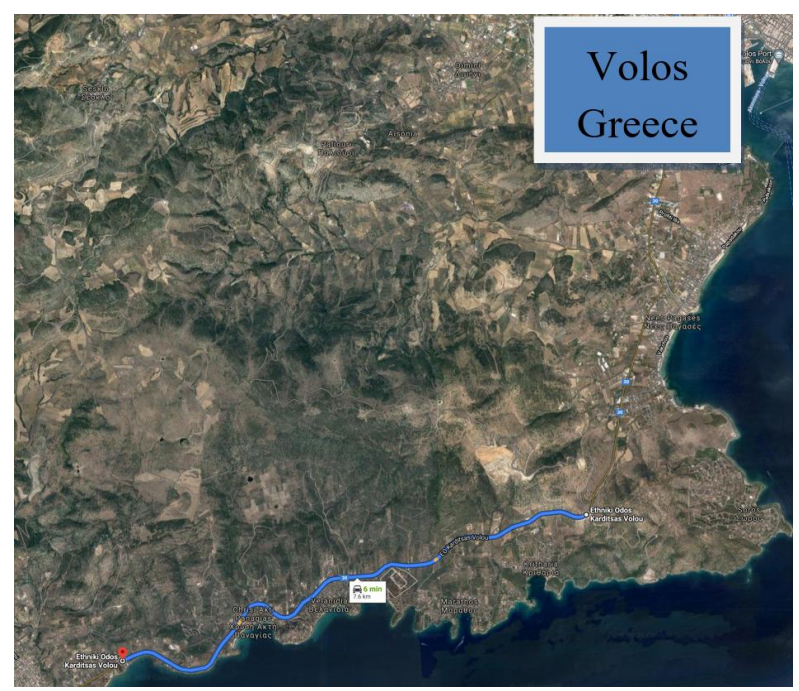

Fig. 1: Experimental route

\subsection{Participants}

Nine participants executed the measurements during daylight whereas the remaining nine during nighttime (Table 1). The selection of the day and the exact time of the measurements was such that the interference from other road users to the participants' behavior was limited and hence the recorded speeds were considered as free flow ones.

The mean age of all the participants $(n=18)$ at the time of the measurements was 40.4 years (standard deviation (std. dev.) $=9.9$ years). They were all experienced riders with a mean valid riding license of 19.5 years (std. dev. $=11.9$ years). They were all owners of at least one registered motorcycle while their riding hours ranged from 1 to 8 per day (mean $=2.83$ hours, std. dev. $=1.99$ hours). Lastly, 15 out of 18 participants used their bike daily with the rest 3 a few times per week. It is therefore apparent that the participants are experienced riders. That was crucial for the effective execution of the measurements since the likelihood of accidents was limited.

\subsection{Instrumented vehicle}

The common practice to record speed data is the use of radar guns and/or speed detectors [7, 12, 13]. However, although both methods are handy and cost-effective, doubts about their validity were discussed in a relevant research study [5] due to technical or human behavior errors. The alternative method to record riding performance data is the use of equipment embedded on the experimental vehicle and that method was used in the field measurements 
of the present study. The instrumented motorcycle constituted of a GPS receiver and an HD camera attached on the luggage rack and between the windscreen and the headlamps of the motorcycle respectively (Fig. 2).

The vehicle that was employed to carry out the field measurements was a mid-weight sport touring motorcycle very much prevalent on the Greek road network manufactured in 2007. The technical specifications of the motorcycle allowed the riders to smoothly cope with the irregularities of a typical pavement which consists of scattered potholes, sedimentation parts, puddles etc. It is equipped with ABS brakes rendering the specific motorcycle very friendly for rural and urban riding. All the participants rode the specific motorcycle before the commencement of the field measurements until they felt familiar with its handling.

Table 1: Participants characteristics

\begin{tabular}{|c|c|c|c|c|}
\hline Rider* & $\begin{array}{c}\text { Age } \\
\text { (years) }\end{array}$ & $\begin{array}{l}\text { Valid } \\
\text { license } \\
\text { (years) }\end{array}$ & $\begin{array}{l}\text { Riding } \\
\text { hours } \\
\text { per day }\end{array}$ & $\begin{array}{l}\text { Riding } \\
\text { frequency }\end{array}$ \\
\hline D1 & 35 & 16 & 1.5 & Daily \\
\hline D2 & 39 & 20 & 1 & Daily \\
\hline D3 & 43 & 23 & 5 & Daily \\
\hline D4 & 58 & 40 & 2.5 & Daily \\
\hline D5 & 32 & 14 & 6 & $\begin{array}{l}\text { Weekly } \\
\text { or more }\end{array}$ \\
\hline D6 & 38 & 2.5 & 4 & Daily \\
\hline D7 & 30 & 12 & 1 & Daily \\
\hline D8 & 63 & 45 & 3 & Daily \\
\hline D9 & 42 & 24 & 1 & $\begin{array}{l}\text { Weekly } \\
\text { or more }\end{array}$ \\
\hline Mean & 42.2 & 21.8 & 2.78 & \\
\hline Std. dev. & 11.3 & 13.4 & 1.87 & \\
\hline N1 & 50 & 29 & 2 & Daily \\
\hline N2 & 49 & 30 & 3 & Daily \\
\hline N3 & 33 & 15 & 1 & $\begin{array}{l}\text { Weekly } \\
\text { or more }\end{array}$ \\
\hline N4 & 45 & 27 & 1 & Daily \\
\hline N5 & 38 & 17 & 3 & Daily \\
\hline N6 & 28 & 3 & 4 & Daily \\
\hline N7 & 26 & 2 & 1 & Daily \\
\hline $\mathrm{N} 8$ & 37 & 12 & 8 & Daily \\
\hline N9 & 41 & 20 & 3 & Daily \\
\hline Mean & 35.8 & 16.8 & 2.79 & \\
\hline Std. dev. & 8.6 & 10.4 & 2.20 & \\
\hline
\end{tabular}

* $\mathrm{D}$ for daylight and $\mathrm{N}$ for night-time

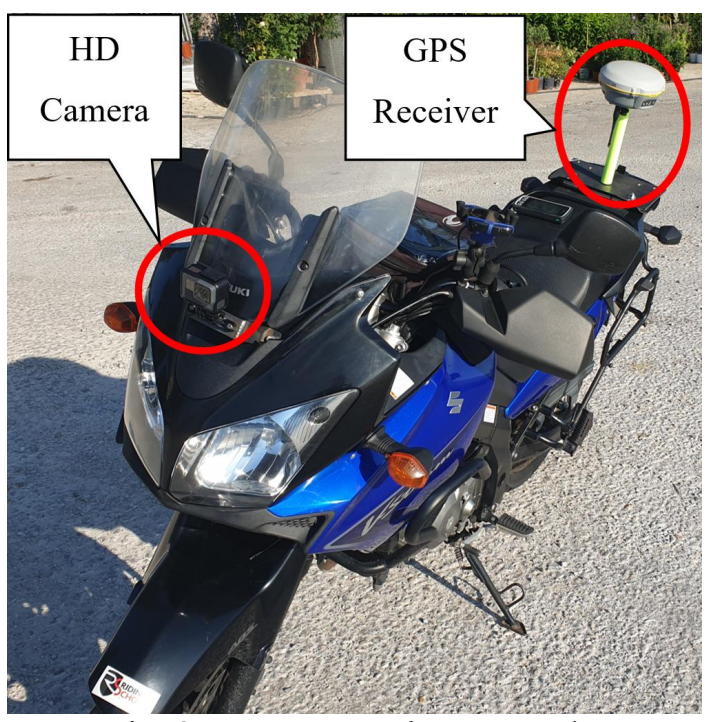

Fig. 2: Instrumented motorcycle

The model of the GPS receiver was the Global Navigation Satellite System (GNSS) receiver Stonex S9 III [22]. The accuracy of the recordings according to the manufacturer of the equipment was as follows:

- Horizontal axis x-y (plane): $0.02 \mathrm{~m}$.

- Vertical axis z (elevation from sea level): $0.05 \mathrm{~m}$.

- Recording rate: $5 \mathrm{~Hz}$.

\subsection{Execution of the field measurements}

The on-the-fly operation of the GNSS receiver was accomplished through the constant transmission to the CivilShop networks [14]. It must be noted that the coordinates of the riders' trajectories were recorded on the Greek Geodetic Reference System 87. The coordinates of each rider were then imported to a sophisticated road design software for further analysis [15]. The geometry of the road had been calculated in the preliminary stage of the measurements (Fig. 3) and hence the deflection angle, radius, length of the preceding tangents, curve length, rate of curvature, and direction i.e., left, or right-handed, of each one of the horizontal curves were known $[16,21]$ as presented in Table 2.

The utilization of the aforementioned equipment resulted in the recording of the speed and path profile for each rider throughout the 21 horizontal curves. That was accomplished by temporarily store the recordings in the internal storage space of the GPS receiver. At the end of each measurement, the recorded files were copied into an external hard disk leaving the internal storage empty and ready to record the next measurement. A folder including the footage derived from the HD camera and an ASCII file containing the instantaneous position, speed and distance traveled was created and assigned to each one of the 18 measurements. 
Table 2: Curves' attributes

\begin{tabular}{|c|c|c|c|c|c|}
\hline Curve & $\begin{array}{l}\text { Radius } \\
\text { (m) }\end{array}$ & $\begin{array}{l}\text { Length } \\
\text { (m) }\end{array}$ & $\begin{array}{l}\text { Direc- } \\
\text { tion* }\end{array}$ & $\begin{array}{l}\text { Curvature } \\
\text { change rate } \\
\text { (gon } / \mathrm{km})\end{array}$ & $\begin{array}{l}\text { Deflection } \\
\text { (m) }\end{array}$ \\
\hline K1 & 900 & 216.50 & $\mathrm{RH}$ & 56.22 & 0.091 \\
\hline $\mathrm{K} 2$ & 250 & 260.64 & $\mathrm{RH}$ & 215.57 & 0.267 \\
\hline K3 & 330 & 257.25 & LH & 170.19 & 0.116 \\
\hline K4 & 200 & 275.13 & LH & 224.31 & 0.521 \\
\hline K5 & 900 & 268.98 & RH & 67.81 & 0.006 \\
\hline K6 & 800 & 236.24 & LH & 62.73 & 0.130 \\
\hline K7 & 200 & 406.1 & $\mathrm{RH}$ & 279.12 & 0.521 \\
\hline $\mathrm{K} 8$ & 195 & 380.43 & LH & 282.46 & 0.562 \\
\hline K9 & 225 & 144.38 & $\mathrm{RH}$ & 195.85 & 0.366 \\
\hline K10 & 380 & 236.22 & LH & 92.88 & 1.214 \\
\hline K11 & 270 & 257.26 & $\mathrm{RH}$ & 201.84 & 0.212 \\
\hline K12 & 220 & 200.38 & LH & 223.73 & 0.391 \\
\hline K13 & 200 & 240.56 & RH & 252.15 & 0.521 \\
\hline K14 & 600 & 175.71 & $\mathrm{LH}$ & 96.04 & 0.019 \\
\hline K15 & 370 & 329.97 & $\mathrm{LH}$ & 140.35 & 0.416 \\
\hline K16 & 400 & 388.53 & $\mathrm{RH}$ & 136.11 & 0.330 \\
\hline K17 & 300 & 212.45 & LH & 178.91 & 0.154 \\
\hline K18 & 300 & 132.23 & RH & 158.71 & 0.154 \\
\hline K19 & 220 & 138.51 & LH & 194.42 & 0.391 \\
\hline K20 & 220 & 165.80 & $\mathrm{RH}$ & 210.04 & 0.391 \\
\hline K21 & 250 & 177.24 & $\mathrm{RH}$ & 197.18 & 0.267 \\
\hline
\end{tabular}

*LH for left-handed curves, RH for right-handed curves

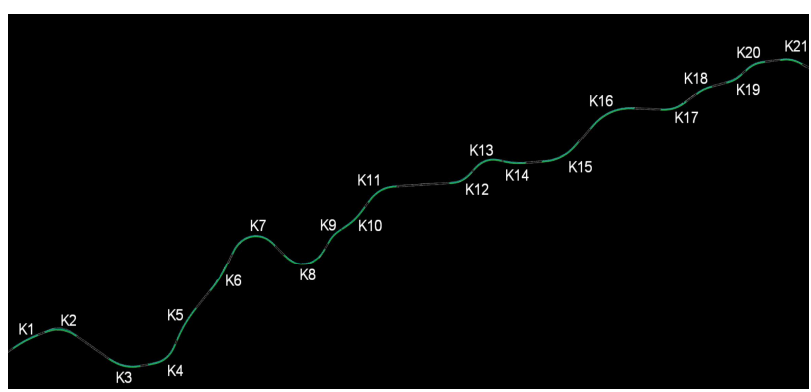

Fig.3: Horizontal curves

\section{Post Process of the Data}

The coordinates of each measurement were then imported into the said road design software for further analysis. The subject of the analysis was the determination of the mean speed of the riders through the horizontal curves. Those speeds were then statistically processed to determine the model that better describes the correlation between them and the geometric attributes of the curves and particularly the curvature change rate.

Since the alignment of the road was already defined, particularly the start and endpoint of every horizontal curve, by importing the points with coordinates $\mathrm{X}, \mathrm{Y}$ of each field measurement in the original drawing it was feasible to determine the recordings that lie in each horizontal curve. Each point was linked with an instantaneous speed value and hence, the mean speeds for each curve and measurement were calculated by averaging the instantaneous speed values within the start and end of each curve. The exact methodology to calculate the mean speeds is described in studies by Lemonakis et al. [23, 24].

For instance, Fig. 4 illustrates this step of the process for a random curve and measurement i.e., Curve K7, measurement of rider 1 in daylight (Rider 1 as presented in Table 1). In this example, the resulting mean speed for the direction Volos to Karditsa was calculated by averaging the instantaneous speed values from point 1108 to point 1183(value $98.50 \mathrm{~km} / \mathrm{h}$ as shown in Table 1) while the mean speed for the direction Karditsa to Volos was calculated by averaging the instantaneous speed values from point 2251 to point 2178 (value $98.03 \mathrm{~km} / \mathrm{h}$ as shown in Table 7) because these points lie in the boundaries of Curve K7. A similar approach was implemented for the rest of the curves and measurements.

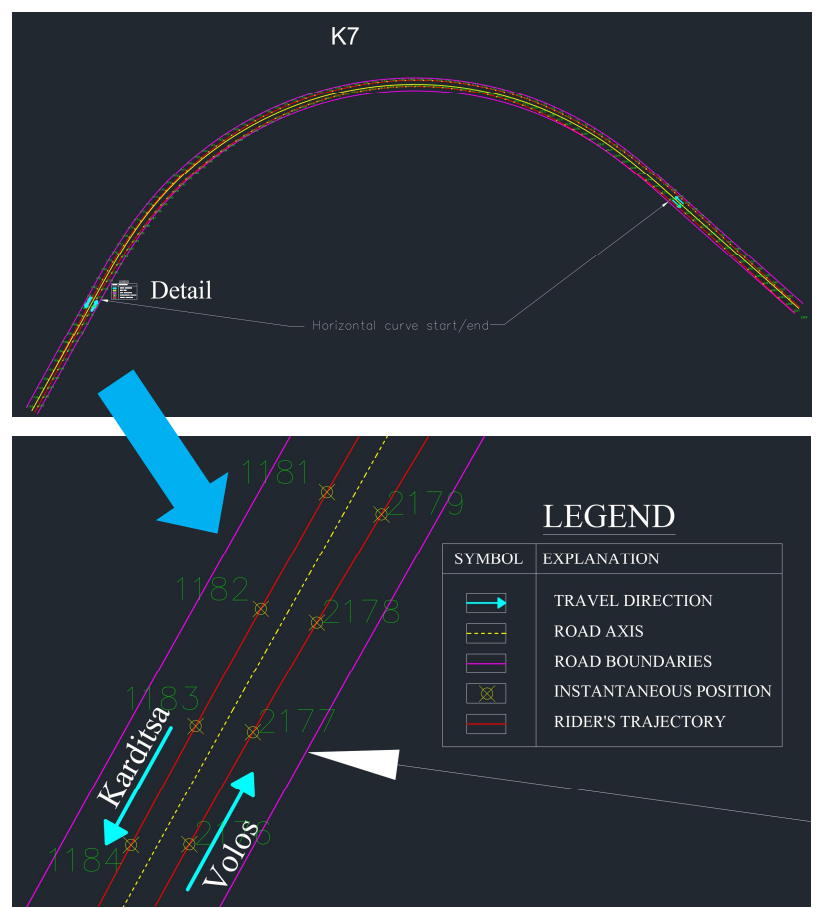

Fig.4: Determination of points along curves

The outcome of this process was the calculation of the mean speed through each curve for every measurement. These data for both directions and lighting conditions (daylight or night-time) are presented in Tables 3 to 6 . 
Table 3: Mean speed $(\mathrm{km} / \mathrm{h})$ for each curve during daylight - Direction from Volos to Karditsa

\begin{tabular}{crrrrrrrrrrr}
\hline Curve & Rider 1 & Rider 2 & Rider 3 & Rider 4 & Rider 5 & Rider 6 & Rider 7 & Rider 8 & Rider 9 & Mean & Std. dev. \\
\hline K1 & 107.73 & 80.61 & 119.99 & 81.00 & 79.92 & 84.48 & 129.21 & 120.81 & 103.44 & 100.80 & 19.79 \\
\hline K2 & 113.14 & 87.99 & 95.74 & 79.10 & 98.40 & 89.34 & 104.97 & 112.16 & 96.47 & 97.48 & 11.27 \\
\hline K3 & 113.07 & 97.30 & 78.88 & 65.13 & 98.61 & 91.02 & 109.38 & 111.28 & 103.85 & 96.50 & 15.98 \\
\hline K4 & 101.50 & 91.30 & 85.63 & 81.77 & 86.99 & 89.79 & 99.15 & 105.25 & 91.63 & 92.56 & 7.83 \\
\hline K5 & 119.15 & 101.05 & 114.37 & 100.33 & 94.52 & 90.31 & 133.75 & 115.29 & 103.45 & 108.02 & 13.71 \\
\hline K6 & 107.58 & 87.22 & 115.84 & 91.08 & 79.58 & 76.30 & 99.37 & 84.52 & 101.44 & 93.66 & 13.28 \\
\hline K7 & 98.50 & 89.11 & 90.62 & 95.53 & 90.48 & 81.91 & 96.31 & 93.22 & 89.63 & 91.70 & 4.92 \\
\hline K8 & 96.93 & 89.24 & 92.18 & 92.62 & 95.67 & 103.95 & 88.65 & 104.88 & 91.63 & 95.08 & 5.92 \\
\hline K9 & 92.08 & 99.00 & 95.86 & 100.84 & 104.54 & 92.92 & 102.91 & 107.04 & 95.59 & 98.98 & 5.25 \\
\hline K10 & 107.86 & 103.07 & 105.04 & 105.92 & 101.35 & 111.24 & 121.82 & 97.71 & 102.49 & 106.28 & 7.01 \\
\hline K11 & 109.88 & 94.23 & 98.23 & 107.18 & 76.09 & 111.57 & 106.78 & 98.36 & 96.12 & 99.83 & 10.92 \\
\hline K12 & 95.47 & 96.30 & 93.75 & 108.32 & 93.89 & 107.96 & 105.60 & 99.42 & 97.00 & 99.75 & 5.95 \\
\hline K13 & 90.46 & 92.72 & 93.17 & 109.49 & 65.76 & 110.24 & 98.22 & 104.68 & 92.10 & 95.20 & 13.41 \\
\hline K14 & 100.29 & 96.97 & 108.56 & 121.84 & 81.57 & 98.11 & 119.98 & 112.23 & 104.82 & 104.93 & 12.53 \\
\hline K15 & 114.68 & 101.80 & 96.30 & 113.24 & 99.25 & 98.11 & 115.33 & 122.61 & 105.16 & 107.39 & 9.31 \\
\hline K16 & 112.02 & 103.51 & 107.37 & 119.09 & 107.24 & 98.11 & 121.85 & 129.41 & 81.23 & 108.87 & 14.22 \\
\hline K17 & 107.01 & 78.81 & 91.81 & 110.59 & 97.14 & 116.54 & 107.90 & 109.34 & 83.41 & 100.28 & 13.15 \\
\hline K18 & 116.15 & 100.19 & 99.70 & 118.02 & 103.54 & 125.94 & 125.21 & 113.50 & 72.22 & 108.27 & 16.75 \\
\hline K19 & 110.45 & 99.70 & 95.24 & 107.23 & 84.74 & 99.24 & 101.23 & 103.49 & 81.34 & 98.07 & 9.66 \\
\hline K20 & 104.81 & 97.68 & 92.95 & 107.02 & 91.04 & 72.30 & 71.19 & 80.53 & 65.03 & 86.95 & 15.31 \\
\hline K21 & 106.23 & 94.76 & 93.91 & 92.53 & 91.52 & 110.98 & 108.31 & 101.16 & 78.63 & 97.56 & 10.16 \\
\hline
\end{tabular}

Table 4: Mean speed $(\mathrm{km} / \mathrm{h})$ for each curve during night time - Direction from Volos to Karditsa

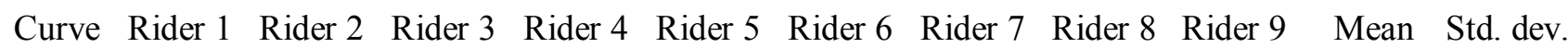

\begin{tabular}{rrrrrrrrrrrr}
\hline K1 & 74.51 & 101.36 & 139.17 & 106.04 & 142.54 & 107.53 & 103.09 & 102.25 & 102.68 & 108.80 & 20.66 \\
\hline K2 & 77.75 & 90.33 & 122.52 & 100.01 & 128.09 & 102.6 & 103.61 & 98.03 & 102.52 & 102.83 & 15.18 \\
\hline K3 & 80.62 & 110.55 & 120.04 & 102.08 & 129.88 & 70.28 & 100.32 & 102.78 & 103.96 & 102.28 & 18.19 \\
\hline K4 & 75.54 & 94.28 & 105.76 & 92.95 & 101.40 & 78.49 & 87.40 & 100.29 & 98.46 & 92.73 & 10.39 \\
\hline K5 & 85.30 & 99.63 & 143.59 & 97.09 & 128.00 & 104.23 & 100.87 & 101.09 & 100.78 & 106.73 & 17.75 \\
\hline K6 & 73.45 & 84.75 & 151.36 & 99.99 & 135.54 & 99.93 & 119.19 & 99.84 & 101.67 & 107.30 & 24.31 \\
\hline K7 & 79.05 & 93.99 & 111.65 & 89.35 & 106.08 & 98.37 & 87.81 & 90.28 & 102.77 & 95.48 & 10.19 \\
\hline K8 & 77.27 & 91.94 & 108.98 & 92.44 & 111.90 & 93.24 & 92.74 & 94.40 & 98.64 & 95.73 & 10.18 \\
\hline K9 & 78.05 & 94.09 & 113.49 & 93.72 & 118.47 & 93.26 & 94.39 & 102.80 & 101.98 & 98.92 & 12.03 \\
\hline K10 & 80.39 & 106.28 & 131.37 & 100.79 & 131.54 & 102.93 & 100.66 & 107.90 & 106.16 & 107.56 & 15.81 \\
\hline K11 & 75.65 & 103.31 & 118.77 & 94.08 & 123.76 & 98.01 & 84.88 & 106.45 & 102.47 & 100.82 & 15.12 \\
\hline K12 & 76.99 & 99.93 & 108.47 & 96.64 & 111.36 & 71.62 & 94.87 & 104.28 & 105.02 & 96.58 & 13.74 \\
\hline K13 & 77.08 & 103.98 & 111.42 & 90.28 & 113.05 & 64.69 & 90.09 & 100.23 & 102.82 & 94.85 & 16.01 \\
\hline K14 & 76.41 & 113.57 & 131.46 & 92.41 & 123.71 & 86.81 & 109.28 & 109.31 & 108.23 & 105.69 & 17.58 \\
\hline K15 & 83.05 & 107.98 & 131.30 & 98.62 & 124.57 & 100.73 & 90.22 & 107.85 & 107.35 & 105.74 & 15.21 \\
\hline K16 & 87.82 & 86.47 & 140.61 & 100.82 & 109.53 & 105.29 & 104.83 & 108.53 & 111.47 & 106.15 & 15.76 \\
\hline K17 & 85.60 & 97.48 & 112.51 & 98.42 & 119.95 & 108.53 & 97.24 & 103.71 & 102.87 & 102.92 & 9.98 \\
\hline K18 & 81.88 & 101.09 & 125.68 & 99.11 & 122.58 & 108.82 & 88.18 & 105.79 & 105.13 & 104.25 & 14.21 \\
\hline K19 & 84.72 & 79.78 & 116.09 & 93.31 & 119.88 & 103.82 & 94.25 & 101.05 & 103.53 & 99.60 & 13.23 \\
\hline K20 & 81.21 & 72.80 & 115.70 & 91.18 & 117.94 & 94.55 & 101.62 & 101.31 & 102.66 & 97.66 & 14.71 \\
\hline K21 & 78.36 & 88.35 & 113.85 & 89.79 & 118.16 & 86.58 & 87.95 & 100.85 & 99.80 & 95.97 & 13.27 \\
\hline
\end{tabular}


Table 5: Mean speed $(\mathrm{km} / \mathrm{h})$ for each curve during daylight - Direction from Karditsa to Volos

\begin{tabular}{rrrrrrrrrrrr}
\hline Curve & Rider 1 & Rider 2 & Rider 3 & Rider 4 & Rider 5 & Rider 6 & Rider 7 & Rider 8 & Rider 9 & Mean & Std. dev. \\
\hline K1 & 142.27 & 97.76 & 124.70 & 123.04 & 98.81 & 128.35 & 133.30 & 113.02 & 106.56 & 118.65 & 15.53 \\
\hline K2 & 114.07 & 97.91 & 105.70 & 101.55 & 89.77 & 98.52 & 111.01 & 78.21 & 99.88 & 99.62 & 10.83 \\
\hline K3 & 128.98 & 101.18 & 107.98 & 112.36 & 103.09 & 121.04 & 113.09 & 109.23 & 102.23 & 111.02 & 9.21 \\
\hline K4 & 113.82 & 93.63 & 94.72 & 98.50 & 100.70 & 109.71 & 98.88 & 99.96 & 87.04 & 99.66 & 8.10 \\
\hline K5 & 120.82 & 99.43 & 114.55 & 91.04 & 101.89 & 113.05 & 121.26 & 101.88 & 103.84 & 107.53 & 10.37 \\
\hline K6 & 94.05 & 83.30 & 101.88 & 88.73 & 83.43 & 101.88 & 135.78 & 83.34 & 102.79 & 97.24 & 16.66 \\
\hline K7 & 98.03 & 84.77 & 92.06 & 95.23 & 76.42 & 101.88 & 96.62 & 89.51 & 87.99 & 91.39 & 7.74 \\
\hline K8 & 106.68 & 72.34 & 94.82 & 98.27 & 81.30 & 105.94 & 98.44 & 97.59 & 91.01 & 94.04 & 11.15 \\
\hline K9 & 100.81 & 67.46 & 92.46 & 96.51 & 105.00 & 101.67 & 100.74 & 97.64 & 93.41 & 95.08 & 11.11 \\
\hline K10 & 109.92 & 80.02 & 104.09 & 110.87 & 109.91 & 118.39 & 115.52 & 97.78 & 100.58 & 105.23 & 11.56 \\
\hline K11 & 115.92 & 92.64 & 104.93 & 111.52 & 106.49 & 118.28 & 87.51 & 102.90 & 100.28 & 104.50 & 10.15 \\
\hline K12 & 112.54 & 92.49 & 97.74 & 98.74 & 102.09 & 110.01 & 106.68 & 105.62 & 89.89 & 101.76 & 7.71 \\
\hline K13 & 107.26 & 92.11 & 82.63 & 104.27 & 99.89 & 105.06 & 103.01 & 105.59 & 95.13 & 99.44 & 8.08 \\
\hline K14 & 117.52 & 92.50 & 87.45 & 120.81 & 104.48 & 108.81 & 121.58 & 119.84 & 101.28 & 108.25 & 12.75 \\
\hline K15 & 122.01 & 83.75 & 105.06 & 121.05 & 92.67 & 115.60 & 124.85 & 121.88 & 86.86 & 108.19 & 16.50 \\
\hline K16 & 125.98 & 94.00 & 101.88 & 115.33 & 113.85 & 115.05 & 125.00 & 121.87 & 106.71 & 113.30 & 10.75 \\
\hline K17 & 98.41 & 93.97 & 101.88 & 84.25 & 101.97 & 111.93 & 105.09 & 85.41 & 100.77 & 98.19 & 8.99 \\
\hline K18 & 75.92 & 89.05 & 101.88 & 99.13 & 90.09 & 116.18 & 69.95 & 104.39 & 79.09 & 91.74 & 15.04 \\
\hline K19 & 84.90 & 85.34 & 108.47 & 107.25 & 101.35 & 113.56 & 113.41 & 104.25 & 71.01 & 98.84 & 14.91 \\
\hline K20 & 74.78 & 88.27 & 104.02 & 96.52 & 97.53 & 104.27 & 110.89 & 106.17 & 65.65 & 94.23 & 15.26 \\
\hline K21 & 107.50 & 84.50 & 104.53 & 105.54 & 97.62 & 106.90 & 111.15 & 102.67 & 93.46 & 101.54 & 8.32 \\
\hline
\end{tabular}

Table 6: Mean speed $(\mathrm{km} / \mathrm{h})$ for each curve during night time - Direction from Karditsa to Volos

Curve Rider 1 Rider 2 Rider 3 Rider 4 Rider 5 Rider 6 Rider 7 Rider 8 Rider 9 Mean Std. dev.

\begin{tabular}{rrrrrrrrrrrr}
\hline K1 & 98.02 & 105.47 & 136.95 & 113.87 & 124.80 & 80.56 & 125.45 & 101.08 & 104.05 & 110.03 & 17.12 \\
\hline K2 & 97.87 & 101.65 & 117.71 & 100.52 & 125.54 & 69.93 & 106.50 & 101.08 & 102.31 & 102.57 & 15.28 \\
\hline K3 & 68.98 & 102.68 & 84.09 & 100.15 & 111.83 & 60.64 & 92.74 & 91.21 & 103.44 & 90.64 & 16.83 \\
\hline K4 & 63.77 & 97.99 & 96.70 & 93.46 & 96.60 & 89.93 & 87.89 & 85.48 & 97.35 & 89.91 & 10.79 \\
\hline K5 & 73.72 & 101.10 & 77.09 & 110.44 & 136.40 & 106.36 & 108.96 & 97.65 & 100.42 & 101.35 & 18.58 \\
\hline K6 & 90.89 & 86.67 & 124.72 & 99.78 & 145.87 & 102.66 & 119.65 & 95.61 & 108.81 & 108.30 & 18.86 \\
\hline K7 & 80.37 & 87.63 & 95.96 & 85.56 & 84.83 & 93.47 & 101.08 & 84.65 & 101.08 & 90.51 & 7.62 \\
\hline K8 & 80.86 & 94.96 & 107.25 & 89.42 & 108.89 & 88.27 & 72.24 & 88.87 & 101.08 & 92.43 & 12.00 \\
\hline K9 & 81.81 & 88.27 & 106.69 & 101.73 & 118.42 & 93.97 & 68.77 & 95.15 & 81.46 & 92.92 & 14.93 \\
\hline K10 & 83.62 & 106.14 & 102.29 & 110.80 & 134.34 & 101.11 & 102.79 & 97.58 & 103.80 & 104.72 & 13.40 \\
\hline K11 & 81.85 & 103.37 & 109.41 & 110.81 & 131.23 & 103.65 & 95.36 & 97.19 & 102.73 & 103.96 & 13.37 \\
\hline K12 & 83.02 & 85.63 & 110.38 & 94.53 & 120.42 & 99.81 & 89.10 & 94.54 & 102.97 & 97.82 & 12.06 \\
\hline K13 & 81.26 & 80.79 & 113.29 & 97.26 & 119.92 & 103.91 & 89.17 & 95.75 & 99.37 & 97.86 & 13.28 \\
\hline K14 & 93.18 & 92.84 & 127.88 & 110.51 & 131.32 & 110.07 & 114.00 & 97.41 & 104.05 & 109.03 & 13.93 \\
\hline K15 & 90.09 & 85.11 & 126.71 & 107.45 & 142.03 & 107.46 & 109.69 & 95.98 & 110.01 & 108.28 & 17.69 \\
\hline K16 & 86.34 & 109.46 & 119.48 & 102.91 & 139.11 & 107.00 & 105.14 & 100.15 & 108.51 & 108.68 & 14.42 \\
\hline K17 & 91.52 & 110.83 & 122.89 & 70.24 & 121.85 & 107.08 & 92.61 & 93.39 & 108.85 & 102.14 & 16.81 \\
\hline K18 & 92.87 & 110.79 & 125.00 & 71.78 & 138.24 & 106.80 & 105.61 & 96.06 & 111.01 & 106.46 & 19.01 \\
\hline K19 & 95.42 & 95.78 & 132.30 & 82.41 & 135.29 & 101.08 & 110.40 & 95.06 & 108.30 & 106.23 & 17.64 \\
\hline K20 & 87.89 & 100.55 & 117.57 & 77.24 & 126.15 & 101.08 & 98.52 & 95.65 & 107.49 & 101.35 & 14.66 \\
\hline K21 & 86.69 & 94.87 & 120.08 & 82.19 & 122.51 & 101.08 & 102.62 & 94.89 & 108.11 & 101.45 & 13.75 \\
\hline
\end{tabular}




\section{Development of the Models}

The calculation of the mean speeds which are assumed that coincide with the operating speeds, followed by the implementation of the ordinary least square regression method aiming at determining the optimum regression curve that better describes the distribution of the collected data.

The mean velocity was considered as the dependent variable, while the curvature change rate $\left(\mathrm{K}_{\mathrm{e}}\right)$ of every horizontal curve as the independent one. The reason behind this decision is that strong evidence suggests that the curvature is the most important factor in determining the operating speed on horizontal curves [17]. The analysis was initially performed separately for each direction and lighting condition. However, in the second stage, the lighting conditions were not taken into account for the development of the models.

The software that was used for the process of the recorded data i.e. the development of the regression models, was the SPSS. Aiming at developing simple regression models, the analysis was linear as many of the speed prediction models that were developed so far $[18,19,20]$.

Therefore, the general form of the speed prediction model in the present study was the following:

$$
\mathrm{U}_{\text {mean }}=\mathrm{A}+\mathrm{B} \cdot \mathrm{K}_{\mathrm{e}}
$$

where: $U_{\text {mean }}=$ the mean speed in the curves $(\mathrm{km} / \mathrm{h})$ $\mathrm{K}_{\mathrm{e}}=$ the curvature change rate $(\mathrm{gon} / \mathrm{km})$

$\mathrm{A}, \mathrm{B}=$ constants

Based on the preceding analysis, Tables 7 and 8 present the developed models separately for the two directions of the experimental route and the corresponding coefficient of determination $\left(\mathrm{R}^{2}\right)$.

Table 7: Speed prediction models for the direction Volos -Karditsa

\begin{tabular}{|c|c|}
\hline \multicolumn{2}{|l|}{ Volos to Karditsa - Daylight } \\
\hline Regression equation & $\mathrm{R}^{2}$ \\
\hline $\mathrm{U}_{\text {mean }}=108.729-0.053 \cdot \mathrm{K}_{\mathrm{e}}$ & 0.322 \\
\hline \multicolumn{2}{|c|}{ Volos to Karditsa - Night-time } \\
\hline Regression equation & $\mathrm{R}^{2}$ \\
\hline $\mathrm{U}_{\text {mean }}=113.922-0.069 \cdot \mathrm{K}_{\mathrm{e}}$ & 0.766 \\
\hline \multicolumn{2}{|c|}{ Volos to Karditsa - Aggregate } \\
\hline Regression equation & $\mathrm{R}^{2}$ \\
\hline $\mathrm{U}_{\text {mean }}=111.325-0.061 \cdot \mathrm{K}_{\mathrm{e}}$ & 0.636 \\
\hline
\end{tabular}

Table 8: Speed prediction models for the direction Karditsa - Volos

\begin{tabular}{|c|c|}
\hline \multicolumn{2}{|c|}{ Karditsa to Volos - Daylight } \\
\hline Regression equation & $\mathrm{R}^{2}$ \\
\hline $\mathrm{U}_{\text {mean }}=114.174-0.071 \cdot \mathrm{K}_{\mathrm{e}}$ & 0.400 \\
\hline \multicolumn{2}{|c|}{ Karditsa to Volos - Night-time } \\
\hline Regression equation & $\mathrm{R}^{2}$ \\
\hline $\mathrm{U}_{\text {mean }}=115.304-0.079 \cdot \mathrm{K}_{\mathrm{e}}$ & 0.470 \\
\hline \multicolumn{2}{|c|}{ Karditsa to Volos - Aggregate } \\
\hline Regression equation & $\mathrm{R}^{2}$ \\
\hline $\mathrm{U}_{\text {mean }}=114.737-0.075 \cdot \mathrm{K}_{\mathrm{e}}$ & 0.604 \\
\hline
\end{tabular}

\section{Conclusions}

The preceding analysis allows the following conclusions to be drawn:

- The regression models that correspond to the night-time measurements provide larger coefficients of determination. Therefore, the operating speeds of motorcycle riders during night-time in 2-lane rural roads are better predicted compared to daylight.

- The aggregate developed models i.e. models that do not take into account the effect of the lighting conditions, provide a reasonably good coefficient of determination.

- As was initially predicted, the value of the curvature change rate negatively affects the operating speed. That is explained by the sign $(-)$ before the multiplier of $\mathrm{K}_{\mathrm{e}}$. Consequently, the more the Curvature Change Rate the less the predicted operating speed.

- For $\mathrm{K}_{\mathrm{e}}=0$ the models give the value of the operating speeds for tangents. In both directions, this value is greater for the field measurements during night-time.

\section{Recommendations}

Numerous studies have shown that operating speed models vary significantly depending on the area, the vehicle type and, the road network (e.g. urban or rural) under study due to either demographic reasons, driver attitudes or, the law enforcement policy among the countries. Consequently, a lot of models have been developed to predict operating speed for both horizontal curves and tangents [17].

The aim of the present study is the development of speed prediction models for motorcycle riders traveling on 2-lane rural roads. The dependent variable i.e. speed, derived from field measurements carried out in both directions of a road segment during daylight and night-time using an 
instrumented motorcycle whereas the geometric attributes of the experimental road were already known from a previous study.

Since the coefficients of determination for the developed models are not particularly large, the incorporation of more geometric attributes to the models is recommended, e.g. longitudinal grade, lane width, deflection angle. Apparently, the analysis should distinguish only those parameters that are statistically significant and have been used in previous studies [5].

Lastly, the lighting conditions differentiate the developed regression models and hence further research is recommended to investigate the role of lighting conditions to the operating speeds. The ultimate goal should be the development of a unique model, either linear or non-linear, which precisely predicts the speed of all vehicle types.

\section{References:}

[1] Mohan, D., Tiwari, G., Khayesi, M., Nafukho, F.M., Road Traffic Injury Prevention: Training Manual, World Health Organization, 2006.

[2] UK Parliament, House of Commons, Transport, Local Government and the Regions, The Consequences of Speed, Transport, Local Government and the Regions Committee Publications, Session 2001-02, 2002.

[3] Yannis, G., Louca, G., Vardaki, S., Kanellaidis, G., Why do Drivers Exceed Speed Limits, European Transport Research Review, Vol.5, No.3, 2013, pp. 165-177.

[4] Donnell, E., Kersavage, K., Tierney, L.F., SelfEnforcing Roadways: A Guidance Report, U.S. Department of Transportation, Federal Highway Administration, 2018.

[5] Transportation Research Circular E-C151, Modeling Operating Speed: Synthesis Report, Transportation Research Board, Washington D.C., 2011.

[6] Perco, P., Comparison between Powered TwoWheeler and Passenger Car Free-Flow Speeds in Urban Areas, Transportation Research Record, Vol. 2074, No.1, 2008, pp. 77-84.

[7] Faezi, S.F., Hamid, H., Davoodi, S.R., Predicting Speed Model of Horizontal Curves on Exclusive Motorcycle Lane, Australian Journal of Basic and Applied Sciences, Vol.5, No.5, 2011, pp. 590-598.

[8] Lamm, R., Psarianos, B., Cafiso, S., Safety Evaluation Process for Two-Lane Rural Roads: A 10-Year Review, Transportation Research Record, Vol.1796, No.1, 2002, pp. 51-59.
[9] Ahmed, M.S., Hashim, I., Impact of Horizontal Alignment on Traffic Performance at Rural Two-Lane Highways, $4^{\text {th }}$ International Symposium on Highway Geometric Design, June 2-5, 2010, Valencia, Spain.

[10] Fitzpatrick K., Evaluation of Design Consistency Methods for Two-Lane Rural Highways, Executive Summary, U.S. Department of Transportation, Federal Highway Administration, 2000.

[11] Praticò, F.G., Giunta, M., Modeling Operating Speed of Two-Lane Rural Roads, Procedia Social and Behavioral Sciences, Vol. 53, 2012, pp. 664-671.

[12] Praticò, F.G., Giunta, M., Operational and Safety Effects of Two-Lane Roads Alignment, $4^{\text {th }}$ International Symposium on Highway Geometric Design, June 2-5, 2010, Valencia, Spain.

[13] Castro, M., Sanchez, J., Ardila, N., Melo, J., Speed Models for Highway Consistency Analysis - A Colombian Case Study, $4^{\text {th }}$ International Symposium on Highway Geometric Design, June 2-5, 2010, Valencia, Spain.

[14] CivilShop, Available at: http://www.civilshop.gr/

[15] Anadelta Software, Anadelta Tessera / Road Design Software. Available at: https://anadelta.com/index-en.php?s=tessera

[16] Kourkoubas, G., Lemonakis, P., Kaliabetsos, G., Galanis, A., Eliou, N., Surveying and Checking of Safety Criteria on the Existing Highway Volos-Karditsa, $7^{\text {th }}$ Pan-Hellenic Road Safety Conference, October 11-12, 2018, Larissa, Greece.

[17] Hassan, I., Abdel-Wahed, T.A., Mostafa, Y.G., Toward an Operating Speed Profile Model for Rural Two-lane Roads in Egypt, Journal of Traffic and Transportation Engineering, Vol.3, No.1, 2016, pp. 82-88.

[18] Abidin, N.Z., Adnan, M.A., Design Consistency Models on Combined Horizontal and Vertical Alignments: Case Study, Advanced Research in Transportation and Geotechnical Engineering, International Conference on Construction and Building Technology, June 16-20, 2008, Kuala Lumpur, Malaysia.

[19] Lamm, R., Psarianos, B., Mailaender, T., Highway Design and Traffic Safety Engineering Handbook, McGraw-Hill, 1999.

[20] Ottesen, J.L., Krammes, R.A., Speed-Profile Model for a Design-Consistency Evaluation Procedure in the United States, Transportation Research Record, Vol.1701, No.1, 2000, pp. 76-85. 
[21] Kourkoubas, G., Survey and Check of the Geometrical Features of an Existing Road, Bachelor Thesis, University of Thessaly, Volos, Greece, 2018.

[22] STONEX,STONEX® S9III, Available at: https://www.stonex.it/project/s9iii/

[23] Lemonakis, P.V., Eliou, N.E., Botzoris, G.N., Karakasidis, T.E., Contribution to the Investigation of Motorcyclists' Speed Prediction Equations for Two-Lane Rural Roads, Journal of Transportation Technologies, Vol.3, No.3, 2013, pp. 204-213.

[24] Lemonakis, P.V., Eliou, N.E., Karakasidis, T.E., Botzoris, G.N., A New Methodology for Approaching Motorcycle Riders' Behavior at Curved Road Sections, European Transport Research Review, Vol.6, No.3, 2014, pp. 303314.

\section{Contribution of individual authors to the creation of a scientific article (ghostwriting policy)}

Panagiotis Lemonakis contributed to all steps of the present study and particularly he organized, executed and, analyzed the field measurements.

George Botzoris was responsible for the set-up of the field measurements, the post statistical analysis and models calibration.

Athanasios Galanis contributed to the literature review of the study and the post statistical analysis.

Nikolaos Eliou assisted in the recruitment and execution of the field measurements presented in section 3 .

\section{Sources of funding for research presented in a scientific article or scientific article itself}

This research study was conducted under the postdoc scholarship supported by the University of Thessaly and exclusively funded by Stavros Niarchos Foundation.

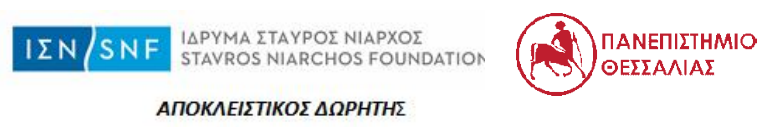

\section{Creative Commons Attribution \\ License 4.0(Attribution 4.0 \\ International, CC BY 4.0)}

This article is published under the terms of the Creative Commons Attribution License 4.0 https://creativecommons.org/licenses/by/4.0/deed.en US 